\title{
Presence of Infectious Bronchitis Virus Strain CK/CH/LDL/97I in the Middle East
}

\author{
Mustafa Ababneh, ${ }^{1}$ Abd Elhafeed Dalab, ${ }^{1}$ Saad Alsaad, ${ }^{1}$ and Mohammad Al-Zghoul, 2 \\ ${ }^{1}$ Faculty of Veterinary Medicine, Jordan University of Science and Technology, P. O. Box 3030, Irbid 22110, Jordan \\ ${ }^{2}$ Faculty of Veterinary Medicine and Animal Resources, King Faisal University, Al-Ihssa 31982, Saudi Arabia
}

Correspondence should be addressed to Mustafa Ababneh, ababnem@just.edu.jo

Received 28 December 2011; Accepted 30 January 2012

Academic Editors: A. Balkema-Buschmann, M. Benko, M. H. Kogut, V. Nair, and A. Shamay

Copyright (C) 2012 Mustafa Ababneh et al. This is an open access article distributed under the Creative Commons Attribution License, which permits unrestricted use, distribution, and reproduction in any medium, provided the original work is properly cited.

Infectious bronchitis virus (IBV) is a very dynamic and evolving virus, causing major economic losses to the global poultry industry. In early 2011, respiratory disease outbreaks were investigated in Iraq, Jordan, and Saudi Arabia. Five IBV isolates (JOA2, JOA4, Saudi-1, Saudi-2, and Iraqi IBV) were detected by diagnostic-nested nucleocapsid RT-PCR. Strain identification was characterised by sequencing and phylogenetic analysis of the amplified hypervariable region of the spike 1 (S1) gene. These five IBV isolates were found to be of the IBV strain CK/CH/LDL/97I. Nucleotide identity between these five IBV isolates ranged from $96.9 \%$ to $99.7 \%$, and between these isolates and the CK/CH/LDL/97I strain in the range of 96.6-99.1\%. The sequenced fragment of the $\mathrm{S} 1$ gene of the $\mathrm{CK} / \mathrm{CH} / \mathrm{LDL} / 97 \mathrm{I}$ strain had less than $80 \%$ nucleotide identity to the IBV vaccine strains commonly used in the Middle East (M41 and H120). The presence of these CK/CH/LDL/97I-like strains may account for vaccination failure against IBV, since all IBV isolates were from vaccinated chickens. In this paper, we documented for the first time the presence of IBV strain CK/CH/LDL/97I in the Middle East. This strain is known to have originated in China and Taiwan.

\section{Introduction}

Infectious bronchitis virus (IBV) is a positive sense singlestranded RNA virus, belonging to the genus Coronavirus, group 3 (gamma coronaviruses) [1]. Infectious bronchitis virus is not only an important pathogen of the respiratory system, but also can be nephropathogenic and cause infection of the reproductive system [2-4]. IBV was first recognised as avian respiratory pathogen in 1930, after that many IBV vaccines were introduced to tackle this problem (H52, H120, M41, 4/91(793/B), and other strains). Recently, different IBV variants have emerged causing nephropathogenic and reproductive problems which require a dramatic change in vaccination programmes $[5,6]$.

IBV strain CK/CH/LDL/97I was first reported in China in 1995 [7]. This strain was first implicated in proventriculitis in chickens [8], but in recent studies, this strain has been isolated from the trachea of infected chickens [9]. IBV $\mathrm{CK} / \mathrm{CH} / \mathrm{LDL} / 97 \mathrm{I}$ strain accounts for $3.2 \%$ of total IBV strains found in China in the last 15 years [9]. The spike glycoprotein gene is the most variable gene in the IBV genome [10] and is composed of S1 and S2 subunits. Spike subunit 1 (S1) is about $1644 \mathrm{nt}$ in length. The S1 protein is highly variable; it can differ from $20 \%$ to $25 \%$ and even up to $50 \%$ in the amino acid sequence among IBV serotypes [11]. This variability makes the S1 gene an ideal target in molecular assays to type IBV strains by RT-PCR and sequencing. The level of homology of the S1 subunit or part of it can predict cross-protection, that is, the higher the homology, the higher the chance of cross-protection $[12,13]$, but this rule is not always fulfilled [3]. Heterologous protection against the $\mathrm{CK} / \mathrm{CH} / \mathrm{LDL} / 97 \mathrm{I}$ strain has not been achieved, since the nucleotide and amino acid homology of the $\mathrm{CK} / \mathrm{CH} / \mathrm{LDL} / 97 \mathrm{I} S 1$ gene is only around 79\% compared to the IBV vaccine strains. Only homologous protection has been achieved against CK/CH/LDL/97I [7].

In the Middle East, the common circulating IBV strains are Mass serotype vaccine isolates, H120 serotype vaccine isolates, D274 [14], IBV variant 1 strains (793/B, IS/222/96, IS/251/96, and IS/64714/96), and variant 2 strains 
(IS/223/96, IS/572/98, IS/585/98, and IS/589/98) [15], along with other unique strains like IS/885/00 [3] and the Egypt/Beni-Seuf/01 strain found in Egypt. By the end of 2009, variant 2 and variant 2 -like strains appeared in Jordan (unpublished data) and in northern Iraq (Sul/01/09) [16].

In the early months of 2011 we noticed IBV outbreaks in spite of massive vaccination, this was due to the presence of a new strain of IBV. In this study, we documented the presence of the IBV strain CK/CH/LDL/97I for the first time in three Middle Eastern countries.

\section{Materials and Methods}

2.1. Tissue Samples and Viral RNA Extraction. Trachea, kidney, ovarian tissues, and cecal tonsils samples were collected from suspected IBV outbreaks in Iraq, Jordan, and Saudi Arabia. These samples were stored at $-70^{\circ} \mathrm{C}$ in RNAlater solution (Qiagen, Germany) until RNA extraction was performed. Homogenised tissues were subjected to viral RNA extraction using the Viral Gene-spin Viral DNA/RNA extraction kit (Intron Biotechnology, Korea). Viral RNA extraction was performed according to the manufacturer's instructions. Viral RNA was stored at $-70^{\circ} \mathrm{C}$ until analysis by RT-PCR.

2.2. RT-PCR (Diagnostic and Phylogenetic). The reversetranscription (RT) step was performed using an RT system (Promega, USA). Briefly, viral RNA was denatured at $70^{\circ} \mathrm{C}$ for 10 minutes, followed by the addition of a reaction mix including $4 \mu \mathrm{L} \mathrm{MgCl}_{2}, 2 \mu \mathrm{L}$ reverse transcription $10 \mathrm{x}$ buffer, $2 \mu \mathrm{L}$ dNTP mixture ( $10 \mathrm{mM}), 0.5 \mu \mathrm{L}$ random primers, $0.75 \mu \mathrm{L}$ AMV reverse transcriptase enzyme, $1 \mu \mathrm{g}$ RNA, and nuclease-free water to a final volume of $20 \mu \mathrm{L}$. Then, the reaction was incubated at $42^{\circ} \mathrm{C}$ for 60 minutes, then $94^{\circ} \mathrm{C}$ for 5 minutes. The cDNA was diluted up to $100 \mu \mathrm{L}$ with nuclease-free water for PCR amplification. Two RT-PCR assays were used. First, a diagnostic-nested RT-PCR assay based on the amplification of the nucleocapsid $(\mathrm{N})$ gene. IBV-specific oligonucleotides for the $\mathrm{N}$ gene were obtained according to a published primers sequences [17]; the IBV primers sequences are presented in Table 1. The diagnostic $\mathrm{N}$ gene amplification was done in a final volume of $25 \mu \mathrm{L}$ GoTaq Green master mix (Promega, USA) in which the final concentration of the $\mathrm{N}$ gene primers was $0.5 \mathrm{mmol}$. RT-PCR amplification was performed with a thermal profile of $94^{\circ} \mathrm{C}$ for $45 \mathrm{sec}, 60^{\circ} \mathrm{C}$ (first step) and $53^{\circ} \mathrm{C}$ (second step) for $1 \mathrm{~min}$ and $72^{\circ} \mathrm{C}$ for $2 \mathrm{~min}$ for 40 cycles.

Next, a phylogenetic RT-PCR was performed using nested spike gene primers according to published protocols $[4,18]$. The amplification profile was the same as that used for $\mathrm{N}$ gene-nested RT-PCR, but the annealing temperature for both RT-PCR steps was $50^{\circ} \mathrm{C}$. Amplification was performed using the GenePro thermal cycler (Bioer, China). Nested S1 gene RT-PCR products were sequenced using an ABI Prism 310 genetic analyser at the Princess Haya Biotechnology Centre (Jordan University of Science and Technology, Jordan). Sequences were aligned using BioEdit (7.0.5.3) and MUSCLE (3.7) software. Aligned sequences were used for phylogenetic analysis. Maximum likelihood (ML) phylogenetic analysis with bootstrap values for $n=$ 100 replicates was performed using the PhyML phylogenetic interface [19]. The nucleotide sequence identities were prepared using CLUSTAL W in the MEGALIGN Programme of the Lasergene software.

\section{Results}

Five IBV isolates were obtained in early 2011. Two IBV isolates were from Jordan (JOA2 and JOA4), two were from Saudi Arabia (Saudi-1 and Saudi-2), and one isolate was from Iraq (Iraqi IBV). The Jordanian isolates were isolated from layer farms at their peak of egg production, the Saudi strains were obtained from broilers and the Iraqi IBV isolate was obtained from a breeder farm as shown in Table 2. According to the clinical and gross examination coupled with the RT-PCR results from the different tissues (trachea, kidney, ovarian tissues, and cecal tonsils), these isolates had an extensive tissue tropism, different than the CK/CH/LDL/97I strain, which has tropism only for the respiratory system. The clinical signs ranged from respiratory to reproductive symptoms; two isolates (JOA2, Iraqi IBV) were implicated in kidney pathology in affected birds.

RT-PCR products of the diagnostic $\mathrm{N}$ gene assay were detected (380 bp) and for the phylogenetic S1 gene (392 bp). Direct-automated sequencing of the second RT-PCR product of nested S1 (SX3 and SX4 primers) was performed. The reference IBV strains included in the $\mathrm{S} 1$ sequence analysis from the United States were M41, Connecticut, DEL072, Ark/15C/96, and Beaudette. The European strains were 4/91, D3896, B1648, and H120. The Australian strains were N1/62 and N1/88. The Chinese strains were IBV LX4, QX IBV, J2, Q1, CK/CH/LDL/97I, and CK/CH/SCYA/10I. Middle Eastern IBV strains were IS/1201, IS/1366, IS/1464, IS/885, variant 1 , variant 2, and Sul/01/09 as shown in Table 3.

All five IBV isolates (JOA2, JOA4, Saudi-1, Saudi2, and Iraqi IBV) were found to be of the IBV strain $\mathrm{CK} / \mathrm{CH} / \mathrm{LDL} / 97 \mathrm{I}$ and therefore they are CK/CH/LDL/97Ilike strains. The $\mathrm{CK} / \mathrm{CH} / \mathrm{LDL} / 97 \mathrm{I}$ strain is known to be endemic in China and Taiwan. The nucleotide identity between these five IBV isolates ranged from 96.9 to $99.7 \%$ with the Saudi-2 isolate being the most divergent. The identity of relatedness between the isolated IBV strains, CK/ $\mathrm{CH} / \mathrm{LDL} / 97 \mathrm{I}$, and the related strain CK/CH/SCYA/10I [20] is shown in Table 4. The Jordanian IBV isolate (JOA2) had a nucleotide identity of $98.1 \%$ and $99.4 \%$ to the CK/ $\mathrm{CH} / \mathrm{LDL} / 97 \mathrm{I}$ and CK/CH/SCYA/10I strains, respectively. For the isolate JOA4, it had $98.8 \%$ and $99.7 \%$ nucleotide identity to the CK/CH/LDL/97I and CK/CH/SCYA/10I strains, respectively. The Saudi IBV isolates had a unique feature, in which isolated Saudi-1 shared $99.1 \%$ and $100 \%$ nucleotide identity to the CK/CH/LDL/97I and CK/CH/SCYA/10I strains, respectively, while the Saudi-2 had only $96.6 \%$ and $97.5 \%$ nucleotide identity to the CK/CH/LDL/97I and CK/CH/SCYA/10I strains, respectively. This could be due to an earlier introduction of this isolate to Saudi Arabia. The Iraqi IBV isolate shared $98.8 \%$ and $99.7 \%$ nucleotide 
TABLE 1: IBV primers for $\mathrm{S} 1$ and $\mathrm{N}$ genes used in this study.

\begin{tabular}{lcc}
\hline IBV primer & Sequence $5^{\prime}$ to $3^{\prime}$ & Position in S1 sequence \\
\hline SX1 & CACCTAGAGGTTTGT/CTA/TGCAT & 677 to $698^{\mathrm{A}}$ \\
SX2 & TCCACCTCTATAAACACCC/TTT & 1148 to 1168 \\
SX3 & TAATACTGGC/TAATTTTTCAGA & 705 to 725 \\
SX4 & AATACAGATTGCTTACAACCACC & 1075 to 1097 \\
\hline & & Position in N sequence \\
\hline N784 & AATTTTGGTGATGACAAGATGA & 763 to $784^{\text {B }}$ \\
N1145 & CATTGTTCCTCTCCTCATCTG & 1145 to 1165 \\
N791 & GTGATGACAAGATGAATGAGGA & 770 to 791 \\
N1129 & CAGCTGAGGTCAATGCTTTATC & 1129 to 1150 \\
\hline
\end{tabular}

${ }^{\mathrm{A}}$ Nucleotide position according to IBV strain 793/B, accession number Z83979.

${ }^{B}$ Nucleotide position according to IBV strain Beaudette, accession number M95169.

TABLE 2: IBV isolates with their tissue tropism (according to the presence of IBV by diagnostic N gene RT-PCR) and clinical history.

\begin{tabular}{|c|c|c|c|c|}
\hline Isolate & Tropism & Clinical findings & Vaccine used & Chicken/age \\
\hline \multirow{3}{*}{ JOA4 } & \multirow{3}{*}{ Trachea, ovary } & Drop in egg production & $\mathrm{H} 120$ & \\
\hline & & Watery cysts in ovaries & M41 & Layer, 24 weeks \\
\hline & & Short and enlarged oviducts & $4 / 91$ & \\
\hline JOA2 & Trachea, kidney, ovary & Drop in egg production & H120, M41, 4/91 & Layer, 22 weeks \\
\hline Saudi-1 & Trachea & Respiratory signs & H120, 4/91 & Broiler, 22 days \\
\hline Saudi-2 & Trachea & Respiratory signs & $\mathrm{H} 120,4 / 91$ & Broiler, 24 days \\
\hline Iraqi IBV & Trachea, kidney & $\begin{array}{l}\text { Respiratory signs, nephritis, and } \\
\text { drop in egg production }\end{array}$ & H120, M41, 4/91 & Breeder, 25 weeks \\
\hline
\end{tabular}

TABLE 3: IBV strains with GenBank accession numbers used in this study.

\begin{tabular}{|c|c|c|}
\hline IBV strain & Tropism & GenBank Accession No. \\
\hline M41 & Respiratory & $\mathrm{M} 21883$ \\
\hline Connecticut & Respiratory & L18990 \\
\hline DEL072 & Respiratory & U77298 \\
\hline Ark/15C/96 & Respiratory & AF169859 \\
\hline Beaudette & Respiratory & X02342 \\
\hline $4 / 91$ & Respiratory & AF093794 \\
\hline D3896 & Respiratory & X52084 \\
\hline B1648 & Nephropathogenic & X87238 \\
\hline $\mathrm{H} 120$ & Vaccine & M21970 \\
\hline LX4 & Proventriculus/nephropathogenic & HM194716 \\
\hline QXIBV & Proventriculus & AF193423 \\
\hline CK/CH/LDL/97I & Respiratory & EF030998 \\
\hline $\mathrm{CK} / \mathrm{CH} / \mathrm{SCYA} / 10 \mathrm{I}$ & Nephropathogenic & HМ363027 \\
\hline $\mathrm{J} 2$ & Proventriculus & AF286303 \\
\hline Q1 & Proventriculus & AF286302 \\
\hline IS/1201 & Respiratory & DQ400359 \\
\hline IS/1366 & Respiratory/nephropathogenic & EU350550 \\
\hline IS/1464 & Respiratory/nephropathogenic & EU780077 \\
\hline IS/885 & Nephropathogenic & AY279533 \\
\hline Variant 1 & Respiratory/nephropathogenic & AF093795 \\
\hline Variant 2 & Respiratory/nephropathogenic & AF093796 \\
\hline Sul/01/09 & Respiratory/nephropathogenic & GQ281656 \\
\hline $\mathrm{N} 1 / 62$ & Nephropathogenic & U29522 \\
\hline $\mathrm{N} 1 / 88$ & Respiratory & U29450 \\
\hline
\end{tabular}


TABLE 4: The identity nucleotide identity of partial S1 among the five IBV isolates compared to the CK/CH/LDL/97I and CK/CH/SCYA/10I strains.

\begin{tabular}{|c|c|c|c|c|c|c|c|}
\hline IBV strain/isolate & JOA2 & JOA4 & Saudi-1 & Saudi-2 & Iraqi IBV & CK/CH/LDL/97I & CK/CH/SCYA/10I \\
\hline JOA2 & 100 & & & & & & \\
\hline JOA4 & 99.1 & 100 & & & & & \\
\hline Saudi-1 & 99.4 & 99.7 & 100 & & & & \\
\hline Saudi-2 & 96.9 & 97.5 & 97.5 & 100 & & & \\
\hline Iraqi IBV & 99.1 & 99.4 & 99.7 & 97.2 & 100 & & \\
\hline CK/CH/LDL/97I & 98.1 & 98.8 & 99.1 & 96.6 & 98.8 & 100 & \\
\hline CK/CH/SCYA/10I & 99.4 & 99.7 & 100 & 97.5 & 99.7 & 99.5 & 100 \\
\hline
\end{tabular}

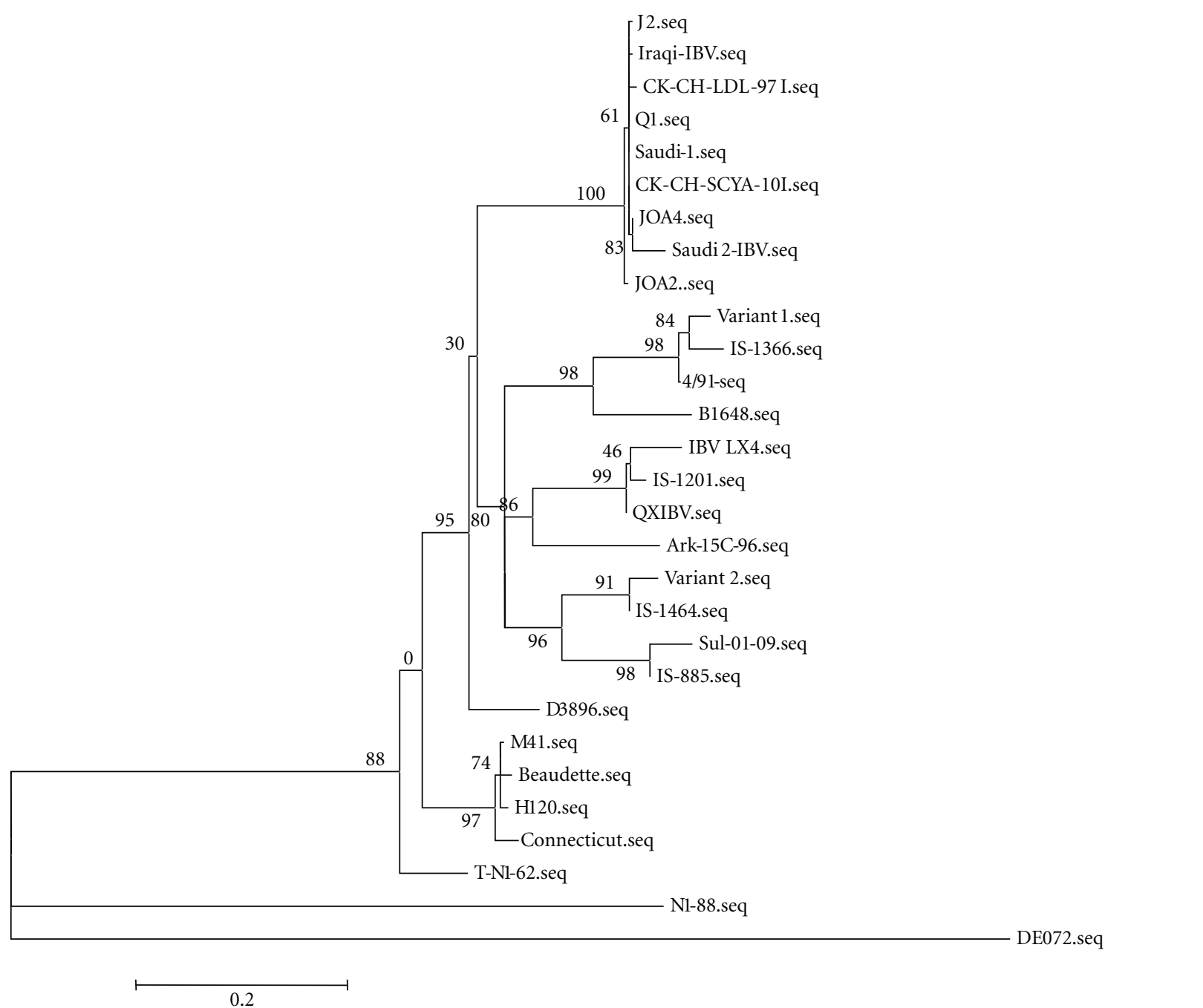

FIgURe 1: Phylogenetic tree for the five IBV isolates and related IBV strains based on the partial S1 sequence.

identity to the CK/CH/LDL/97I and CK/CH/SCYA/10I strains, respectively.

A phylogenetic tree was constructed based on the alignment of the partial S1 sequence. The five IBV isolates were aligned with other reference and related IBV strains as shown in Figure 1. It showed that all five IBV isolates were grouped with CK/CH/LDL/97I, CK/CH/SCYA/10I, J2, and Q1 (both
J2 and Q1 were isolated from the proventriculus) [8] in one group. The nucleotide identity of these five isolates to the IBV vaccine strains in the three countries (M41, H120, and 4/91) were in the range of $78-82.1 \%$, to variant 1 IBV strains in the range of $78.9-81.5 \%$, to variant $2 \mathrm{IBV}$ strains in the range of $81.7-83.6 \%$, and to the IS/885 and Sul/01/09 strains in the range of $78.3-80.9 \%$ (data not shown). 
Also, these IBV isolates represent a group distinct from the LX4 IBV type and from QXIBV and IS/1201 (a Middle Eastern strain) related to it. These strains share only $79 \%$ nucleotide sequence identity. The lowest nucleotide identity was seen with the DEL072 strain (58\%) and with the N1/88 strains (63\%) from Australia.

\section{Discussion}

In this study, the CK/CH/LDL/97I-like strains were isolated from three different Middle Eastern countries (Jordan, Saudi Arabia, and Iraq) in 2011. The CK/CH/LDL/97I-like strains were isolated from broilers in Saudi Arabia, layers in Jordan, and from breeders in Iraq. The CK/CH/LDL/97I-like strain was first isolated in China in 1995 [7]. This strain was isolated from the tracheas of infected chickens [9]. The IBV CK/CH/LDL/97I strains showed slight variability in the partial S1 sequence among IBV isolates from these three countries. The mode transmission of this strain from China to the Middle East is not clear; one reason might be that Chinese poultry vaccines and products have recently been registered and used in the Middle East.

All isolates came from flocks vaccinated with Masstype H120, and 4/91 vaccines, which implies insufficient protection against these isolates. The poor relationship in the partial S1 sequence between the five IBV isolates and the vaccine strains (average nucleotide identity of $80 \%$ ) could explain the failure of the Mass 41, H120, and 4/91 vaccination programmes to control IBV in these flocks [5]. There is no solution to tackle infection coming from these five IBV isolates except to make a homologous vaccine against this strain. Homologous vaccine was made for the IBV, CK/CH/LDL/97I strain found in China, for IBV QX strain and a nephropathogenic IBV strain in Korea [7, 21, 22].

In summary, this is the first paper indicting the presence of the IBV CK/CH/LDL/97I strain outside mainland China and Taiwan (in three Middle Eastern countries). In the near future, we expect that this strain might represent a serious problem for the poultry industry and there will be an urgent need to develop a homologous vaccine against this strain.

\section{Acknowledgments}

This work was funded by a grant from the Deanship of Research at Jordan University of Science and Technology. The authors would like to thank Hazar Shawash from the Jordan Bio-industries Center (JOVAC) for her technical support.

\section{References}

[1] D. Cavanagh, "Severe acute respiratory syndrome vaccine development: experiences of vaccination against avian infectious bronchitis coronavirus," Avian Pathology, vol. 32, no. 6, pp. 567-582, 2003.

[2] K. S. Choi, E. K. Lee, W. J. Jeon, M. J. Park, J. W. Kim, and J. H. Kwon, "Pathogenicity and antigenicity of a new variant of Korean nephropathogenic infectious bronchitis virus," Journal of Veterinary Science, vol. 10, no. 4, pp. 357-359, 2009.
[3] R. Meir, E. Rosenblut, S. Perl et al., "Identification of a novel nephropathogenic infectious bronchitis virus in Israel," Avian Diseases, vol. 48, no. 3, pp. 635-641, 2004.

[4] K. J. Worthington, R. J. W. Currie, and R. C. Jones, "A reverse transcriptase-polymerase chain reaction survey of infectious bronchitis virus genotypes in Western Europe from 2002 to 2006," Avian Pathology, vol. 37, no. 3, pp. 247-257, 2008.

[5] C. Terregino, A. Toffan, M. Serena Beato et al., "Pathogenicity of a QX strain of infectious bronchitis virus in specific pathogen free and commercial broiler chickens, and evaluation of protection induced by a vaccination programme based on the Ma5 and 4/91 serotypes," Avian Pathology, vol. 37, no. 5, pp. 487-493, 2008.

[6] C. Sun, Z. Han, H. Ma et al., "Phylogenetic analysis of infectious bronchitis coronaviruses newly isolated in China, and pathogenicity and evaluation of protection induced by Massachusetts serotype H120 vaccine against QX-like strains," Avian Pathology, vol. 40, no. 1, pp. 43-54, 2011.

[7] S. Liu, X. Zhang, Y. Wang et al., "Evaluation of the protection conferred by commercial vaccines and attenuated heterologous isolates in China against the CK/CH/LDL/97I strain of infectious bronchitis coronavirus," Veterinary Journal, vol. 179, no. 1, pp. 130-136, 2009.

[8] L. Yu, Y. Jiang, S. Low et al., "Characterization of three infectious bronchitis virus isolates from China associated with proventriculus in vaccinated chickens," Avian Diseases, vol. 45, no. 2, pp. 416-424, 2001.

[9] Z. Han, C. Sun, B. Yan et al., "A 15-year analysis of molecular epidemiology of avian infectious bronchitis coronavirus in China," Infection, Genetics and Evolution, vol. 11, no. 1, pp. 190-200, 2011.

[10] M. W. Jackwood, T. O. Boynton, D. A. Hilt et al., "Emergence of a group 3 coronavirus through recombination," Virology, vol. 398, no. 1, pp. 98-108, 2010.

[11] D. Cavanagh, J. P. Picault, R. E. Gough, M. Hess, K. Mawditt, and P. Britton, "Variation in the spike protein of the 793/B type of infectious bronchitis virus, in the field and during alternate passage in chickens and embryonated eggs," Avian Pathology, vol. 34, no. 1, pp. 20-25, 2005.

[12] B. S. Ladman, A. B. Loupos, and J. Gelb Jr., "Infectious bronchitis virus $S 1$ gene sequence comparison is a better predictor of challenge of immunity in chickens than serotyping by virus neutralization," Avian Pathology, vol. 35, no. 2, pp. 127-133, 2006.

[13] D. Cavanagh, M. M. Ellis, and J. K. A. Cook, "Relationship between sequence variation in the S1 spike protein of infectious bronchitis virus and the extent of cross-protection in vivo," Avian Pathology, vol. 26, no. 1, pp. 63-74, 1997.

[14] D. A. Roussan, G. Y. Khawaldeh, and I. A. Shaheen, "Infectious bronchitis virus in Jordanian chickens: seroprevalence and detection," Canadian Veterinary Journal, vol. 50, no. 1, pp. 7780, 2009.

[15] S. A. Callison, M. W. Jackwood, and D. A. Hilt, "Molecular characterization of infectious bronchitis virus isolates foreign to the United States and comparison with United States isolates," Avian Diseases, vol. 45, no. 2, pp. 492-499, 2001.

[16] Z. H. Mahmood, R. R. Sleman, and A. U. Uthman, "Isolation and molecular characterization of Sul/01/09 avian infectious bronchitis virus, indicates the emergence of a new genotype in the Middle East," Veterinary Microbiology, vol. 150, no. 1-2, pp. 21-27, 2011.

[17] A. Farsang, C. Ros, L. H. M. Renstrom, C. Baule, T. Soos, and S. Belak, "Molecular epizootiology of infectious bronchitis 
virus in Sweden indicating the involvement of a vaccine strain," Avian Pathology, vol. 31, no. 3, pp. 229-236, 2002.

[18] R. C. Jones, K. J. Worthington, I. Capua, and C. J. Naylor, "Efficacy of live infectious bronchitis vaccines against a novel European genotype, Italy 02," Veterinary Record, vol. 156, no. 20, pp. 646-647, 2005.

[19] A. Dereeper, V. Guignon, G. Blanc et al., "Phylogeny.fr: robust phylogenetic analysis for the non-specialist," Nucleic Acids Research, vol. 36, pp. W465-469, 2008.

[20] N. L. Zou, F. F. Zhao, Y. P. Wang et al., "Genetic analysis revealed LX4 genotype strains of avian infectious bronchitis virus became predominant in recent years in Sichuan area, China," Virus Genes, vol. 41, no. 2, pp. 202-209, 2010.

[21] H. J. Lee, H. N. Youn, J. S. Kwon et al., "Characterization of a novel live attenuated infectious bronchitis virus vaccine candidate derived from a Korean nephropathogenic strain," Vaccine, vol. 28, no. 16, pp. 2887-2894, 2010.

[22] H. J. Geerligs, G. J. Boelm, C. A. M. Meinders et al., "Efficacy and safety of an attenuated live QX-like infectious bronchitis virus strain as a vaccine for chickens," Avian Pathology, vol. 40, no. 1, pp. 93-102, 2011. 

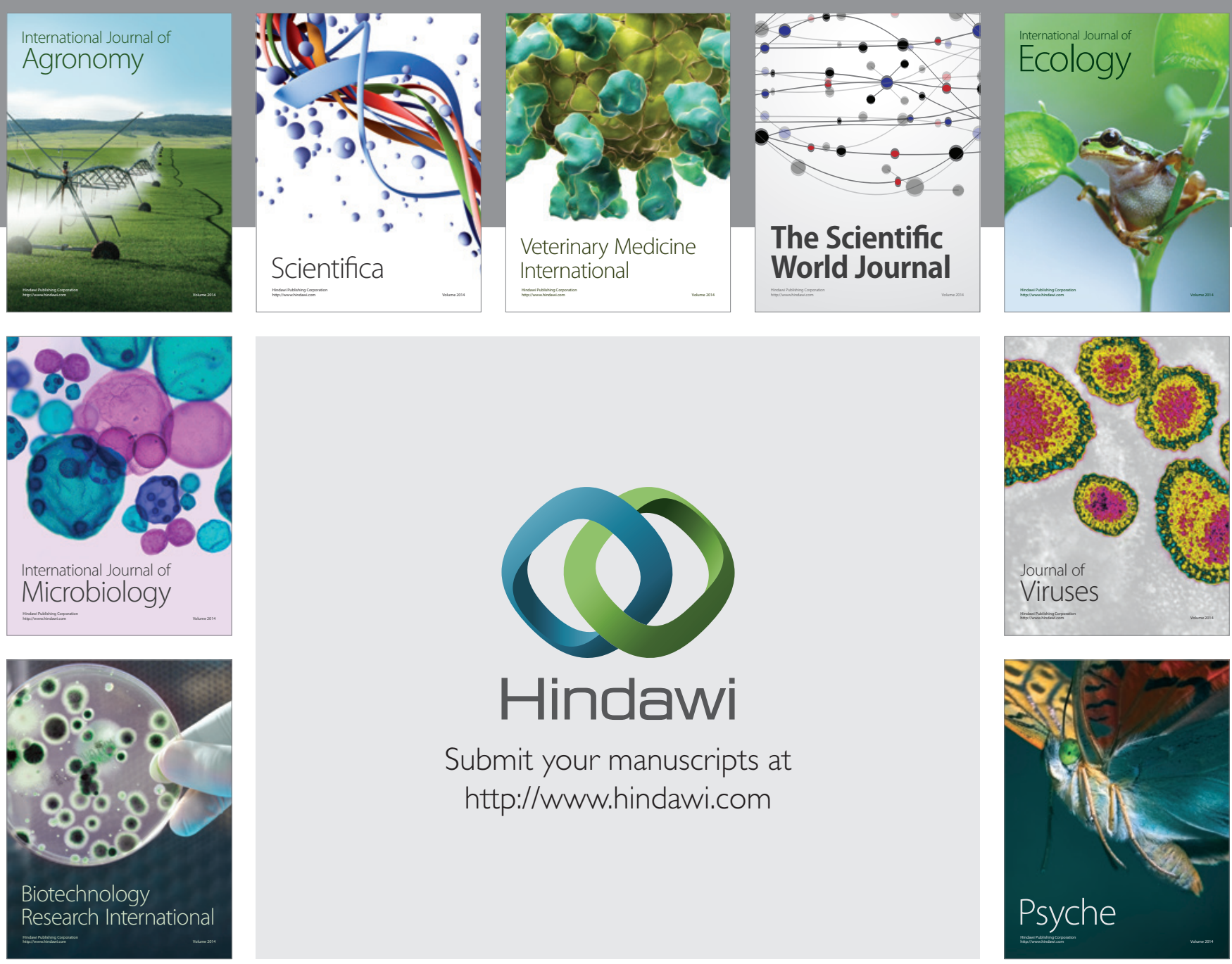

Submit your manuscripts at http://www.hindawi.com
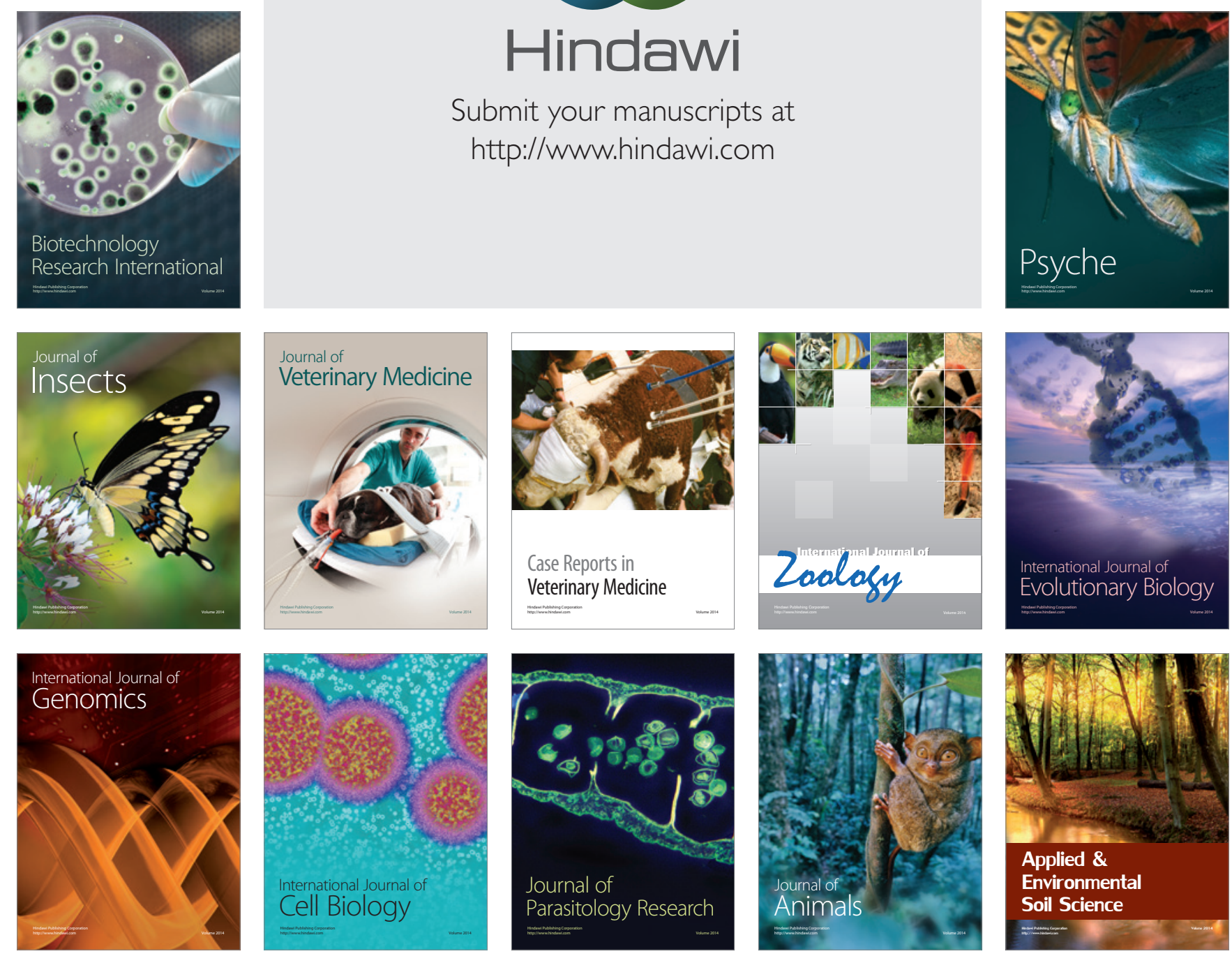